\title{
Study of Heat Transfer through Radially Buffled Rotating Annulus
}

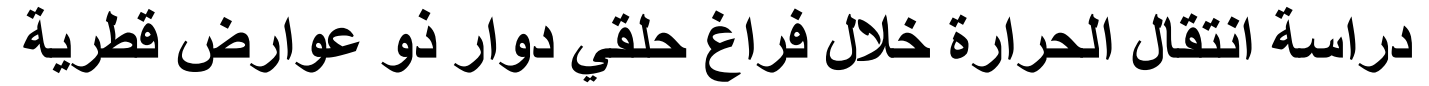

\section{Mohammed Kadhim Hamza ${ }^{(1)}$ Ahmed.A.sultan ${ }^{(1)}$, and Ali.M. Elbouz ${ }^{(1)}$ ${ }^{1}$ Mech. Power Eng.Dept, Faculty of Engineering.}

هذا البحث يقدم دراسة عملية لإنتقال الحرارة بالحمل الجبري الرقائقي لماء بارد ينساب خلال حيز حلقي اسطواني .

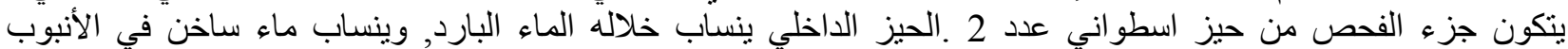

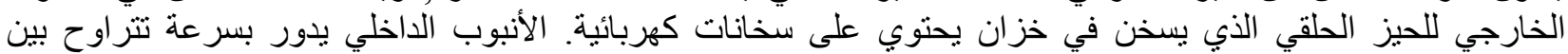

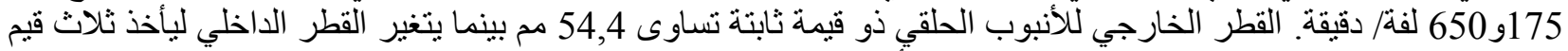

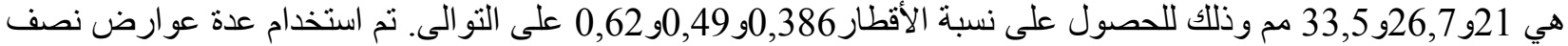

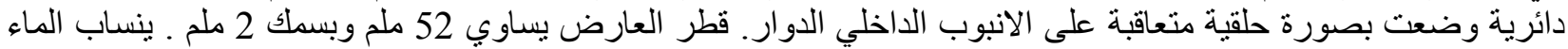

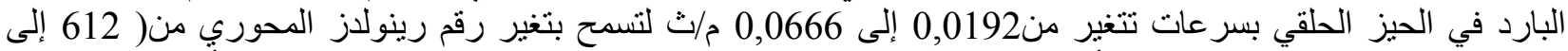

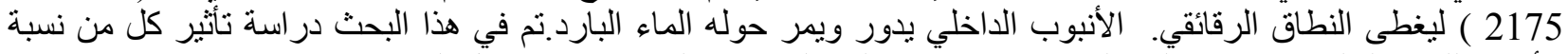

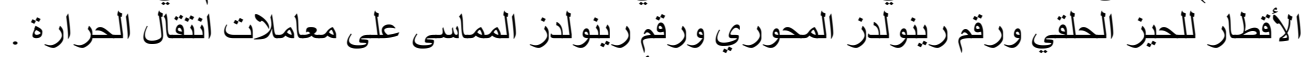

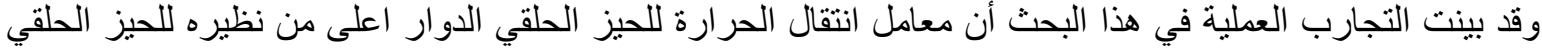

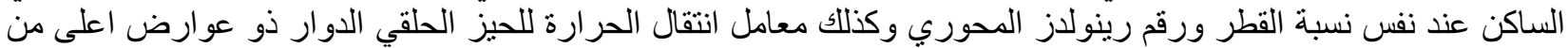

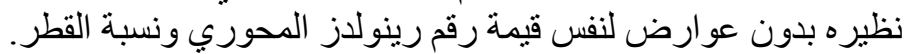

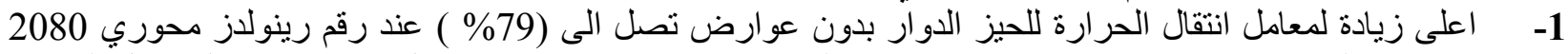

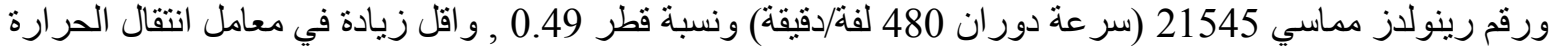
يصل الى 11\% عند رقم رينولدز محوري 646.2 ورقم رينولدز مماسي 7808 (سر عة دور ان

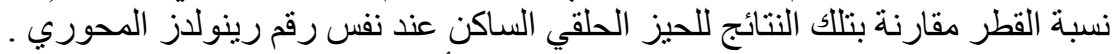

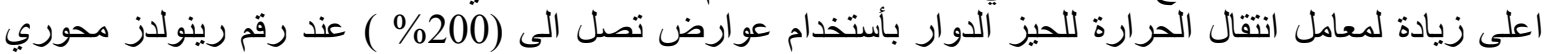

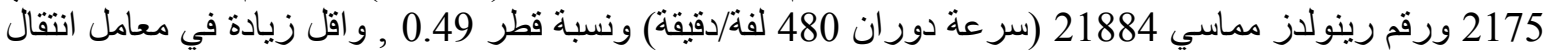
الحرارة يصل الى 84\% عند رقم رينولدز محوري 634 ورقم رينولدز مماسي 21778 ( سرعة دوران 480 لفة /

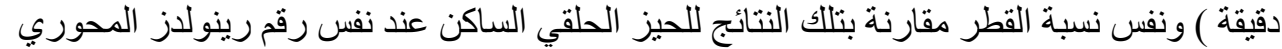

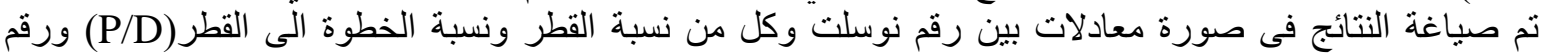

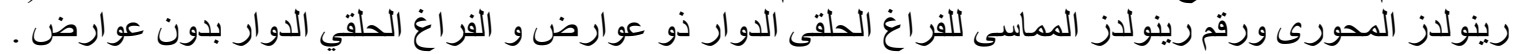

\section{Abstract}

This paper presents an experimental study of laminar forced convection heat transfer for cold water flows through annular tube. The test section consisted of two annular spaces the inner of which for the tested cold water while the outer for the heating water flow that heated in a tank by electrical heaters. The inner tube of the annulus is rotated with rotational speeds which varied from 175 to $650 \mathrm{p} . \mathrm{m}$. The outer tube of the annulus have a constant diameter of $54.5 \mathrm{~mm}$ but the diameter of inner tube of the annulus is equal to $21,26.7$ and $33.5 \mathrm{~mm}$ so as to give diameter ratios of $0.62,0.49$ and 0.386 . Variable numbers of semi-circle of buffles are used circumferentially around the rotating tube. The diameter of buffle is equal to $52 \mathrm{~mm}$ and $2 \mathrm{~mm}$ thickness. Cold water flowed axially through the annular space with velocities that ranged from $(0.0192$ to $0.0666 \mathrm{~m} / \mathrm{s})$, to give axial Reynolds numbers in the range $(612 \leq \operatorname{Re} \leq 2175)$, to cover the laminar flow regime. In the present work the effects of radius ratio, axial Reynolds number and rotational Reynolds number on the heat transfer are investigated. The results show that, the rate of heat transfer of the rotational annular tubes is higher than that of the stationary one of the same radius ratio and axial Reynolds numbers, and the rate of heat transfer of rotational annular tubes with baffles higher than rotational annular tubes without baffles of the same radius ratio and axial Reynolds numbers. 
1- Rotation without buffle, Produces a maximum increase in Nusselt number of the order of $79 \%$ at $\operatorname{Re}_{\mathrm{a}}=2080$, $\operatorname{Re}_{\omega}=21545$ and rotational speed $=480$ r.p.m, (increase of only $11 \%$ in Nusselt number at $\operatorname{Re}_{\mathrm{a}}=646.2, \operatorname{Re}_{\omega}=$ 7808 ,( rotational speed of 175 r.p.m), compared to the results of the stationary annular tube of the same radius ratio .

2- $\quad$ Rotation with buffle, Produces a maximum increase in Nusselt number of $200 \%$ at $\operatorname{Re}_{\mathrm{a}}=2175, \operatorname{Re}_{\omega}=21884$ and rotational speed $=480$ r.p.m, and increase of only $84 \%$ in Nusselt number at $\operatorname{Re}_{\mathrm{a}}=634, \operatorname{Re}_{\omega}=21778$, ( rotational speed of 175 r.p.m) compared to the results of the stationary annular tube of the same radius ratio .

Two correlations are made to describe the relation between Nusselt numbers and axial Reynolds number, diameter ratio, pitch to diameter ratio P/D and rotational Reynolds number and Reynolds number for stationary, rotating and buffled rotating annuli.

\section{Keywords}

Laminar forced convection, heat transfer, annular tube, rotating inner tube, radius ratio

\begin{tabular}{|c|c|c|c|}
\hline \multicolumn{4}{|c|}{ Nomenclature } \\
\hline & $\begin{array}{l}\text { surface area, } \mathrm{m}^{2} \\
\text { cross surface area, } \mathrm{m}^{2} \\
\text { Specific heat } \mathrm{J} / \mathrm{kg} \cdot \mathrm{k}^{\circ} \\
\text { Annulus inner diameter, } \mathrm{m} \\
\text { Annulus outer diameter, } \mathrm{m} \\
\text { Hydraulic diameter, } \mathrm{m} \\
\text { Diameter ratio }\end{array}$ & $\begin{array}{l}\mathrm{u} \\
\mathrm{k} \\
\mathrm{N} \\
\mathrm{T} \\
\mathrm{m} \\
\mathrm{h}\end{array}$ & $\begin{array}{l}\text { Average velocity, } \mathrm{m} / \mathrm{s} \\
\text { thermal conductivity, W/m. } \mathrm{k}^{\circ} \\
\text { speed of rotating inner tube, r.p.m } \\
\text { Temperature, } \mathrm{k}^{\circ} \\
\text { Water mass flow rate, } \mathrm{kg} / \mathrm{s} \\
\text { Convection heat transfer coefficient, } \\
\mathrm{W} / \mathrm{m}^{2} . \mathrm{K}\end{array}$ \\
\hline \multicolumn{4}{|c|}{ Dimensionless numbers } \\
\hline $\begin{array}{l}\mathrm{Nu} \\
\mathrm{Re}_{\mathrm{a}} \\
\operatorname{Re}_{\omega}\end{array}$ & $\begin{array}{l}\text { Nusselt number (-) } \\
\text { Axial Reynolds number (-) } \\
\text { Rotational Reynolds number (-) }\end{array}$ & & \\
\hline \multicolumn{4}{|c|}{ Greek letters } \\
\hline & Kinematic viscosity, $\mathrm{m}^{2} / \mathrm{s}$ & $\dot{\omega}$ & Angular velocity, $\mathrm{rad} / \mathrm{s}$ \\
\hline \multicolumn{4}{|c|}{ Subscripts } \\
\hline & $\begin{array}{l}\text { Cross-sectional area } \\
\text { Based on hydraulic diameter } \\
\text { rotational }\end{array}$ & $\begin{array}{l}\text { a } \\
\text { s } \\
\text { wi } \\
\text { wo }\end{array}$ & $\begin{array}{l}\text { axial } \\
\text { wall } \\
\text { water inlet } \\
\text { water outlet }\end{array}$ \\
\hline
\end{tabular}

\section{1- Introduction}

Heat transfer and fluid flow between concentric cylinders have been intensively investigated because of its basic importance in numerous engineering applications. Practical examples of forced convection between concentric cylinders include flow and heat transfer in double pipe heat exchangers, oil /gas drilling wells, nuclear fuel element cooling system, and plastic extruders, cooling of electric machines, turbo-machinery and journal bearings. Studying this type of flow is needed to improve the machines efficiency by optimizing the heat transfer characteristics and by minimizing the torque required to rotate the rotating parts.

Many engineering applications involve rotating machinery components. They include rotating membrane filters, co-axial rotating heat pipes, rotating extractors, 
cylindrical bearings, and rotating power transmission systems. A basic configuration for rotating machinery components is the annulus with a stationary outer cylinder and a rotating inner cylinder. The flow in such an annulus is called Taylor-Couette flow, in which the famous Taylor vortices damping effect of the imposed axial flow on the internal motions of the vortices. Excessive thermal stress can damage rotating machinery components [12]. This fact has motivated numerous interesting studies on the mechanism of heat transfer in Taylor Couette flow or Taylor- Couette - Poiseuille flow.

\subsection{Annuli with stationary cylinders:}

Reynolds et al.[1] presented for the first time a general formulation of the fully developed forced convection problem in concentric annuli for arbitrarily prescribed wall temperature or heat fluxes. Four fundamental thermal boundary conditions were established (first kind, second kind, third kind and four kind). [2] Solved the governing equations for the heat transfer in annular passages for simultaneously developing velocity and temperature profiles in laminar forced flow. Sparrow and Lin [3] provided the axial velocity distribution and the axial pressure drop for laminar forced flow in the entrance region of concentric annuli. El-Shaarawi and Alkam [4] used finite difference scheme to study the transient laminar forced convection in the entry region with initially step change in temperature at one of the annulus boundaries or a step change in temperature at both inlet cross section and one of annulus boundaries while the other boundary was kept adiabatic. They found that heating the outer boundary effect is much higher than heating the inner boundary. Yoo [5] studied numerically the fully developed mixed convection in an annulus with different walls temperatures with the outer cylinder colder than the inner cylinder. They found three types of flow patterns according to the number of eddy; they are two-eddy, one eddy, and no-eddy flows. Islam et al; [6] investigated numerically the steady laminar mixed convection in the entrance region of a horizontal concentric annulus with uniform heat flux at the inner wall and adiabatic outer wall. They found that Nusselt numbers of air at the entrance region are considerably greater than fully developed values. They found also that axial flow and temperature field development are strongly influenced by the buoyancy especially near the inlet Section. Soares et al [7], Eraslan and Ozbelge [8] and Ilicali and Engez [9] studied the hydrodynamic and heat transfer characteristics of laminar flow inside concentric annuli; their focus was on the non-Newtonian fluids. Sutherland and Kays [10] performed an analysis of a hydro dynamically and thermally fully developed laminar flow in a concentric circular tube annulus with an arbitrarily prescribed heat flux around the periphery of either walls. Contrary to what they expected, they found that the wall temperature variation was very substantial. $\mathrm{Lu}$ et al; [11] studied experimentally the forced convection heat transfer of single-phase water in vertical and horizontal narrow annuli. They found that the heat transferred in a narrow annulus was not the same as that calculated by conventional formulae earmarked for internal flow in round tubes, and the transition from laminar 
to turbulent flow happened markedly earlier than in conventional round tubes.

\subsection{Annuli with rotating cylinders: -}

Tzer-Ming et al [12] investigated experimentally heat transfer enhancement of Taylor-Couette-Poiseuille flow in an annulus by mounting longitudinal ribs on the rotating inner cylinder. Over the range of the axial Reynolds number Re and rotational Reynolds number $\operatorname{Re}_{\omega} ;$ are $30 \leq \mathrm{Re} \leq 1300$ and $0 \leq$ $\operatorname{Re}_{\omega} \leq 2922$, respectively. The value of Nusselt number $\mathrm{Nu}$ is almost minimal at the inlet of the annular channel, and then sharply rises in the axial direction. The average Nusselt number increases with Reynolds number . Nu increases rapidly with $\operatorname{Re}_{\omega}$ at low ( $\mathrm{Re}$ $\leq 60)$. However the effect of $\operatorname{Re}_{\omega}$ decreases as the value increases $(\mathrm{Re} \geq 1200)$ Sultan et al [13] experimentally investigated forced convection heat transfer from outer surface of annular tube with rotating inner tube. They found that the heat transfer of the rotational as well as the stationary annular tubes increase with the decrease of the radius ratio of the annulus, and the heat transfer of the rotational annular tubes is higher than this of the stationary ones at the same radius ratio and axial Reynolds number. Aliean [14] experimentally investigated the overall heat transfer coefficient for a rotating cavity type heat exchanger. The heat exchanger mainly consisted of a rotating cylindrical cavity with axially through flow. Mollo et al. [15] used a mass transfer procedure to study experimentally the laminar flow in the entry region of a circular annulus with rotating inner walls. They got results of Sherwood number versus axial location and reported the critical Taylor number Ta after which Taylor vortices were formed. Choi and Kim [16] studied numerically the fully developed mixed convection in an annulus with a heated rotating inner cylinder. They found that the effect of heating of inner cylinder postpones the formation of Taylor vortices when the rotation effect dominates the buoyancy effect. When the effect of buoyancy predominates over the effect of centrifugal force, the rotation of inner cylinder also stabilizes the two dimensional basic flows. When both rotation and buoyancy effects are important, the basic flow became unstable with respect to oscillatory disturbances. [17] Escudier et al., 1995 experimentally investigated axial, radial and tangential component of velocity and root mean square velocity fluctuations in concentric annular flow for Newtonian and a shear thinning polymer in laminar, transitional and turbulent flow region with a rotating center body of radius ratio is 0.506 . The influence of center body rotation on pressure drop in concentric annular flow is Negligible under turbulent flow conditions for both fluids.

\section{Experimental Test-Rig}

The test rig shown in Fig. 1 consists of the test section (1), hot water system (2), temperature recorder (3). The components of the systems and details will be explained as follows:

\subsection{The test section}

The test section shown in Fig. (2) is the main part of the test rig. It consists mainly of two annuli namely the inner annulus and the outer one. Each one of the annulus consists of two tubes where the inner tube of the outer annulus consists of the outer tube of the inner annulus. The outer annulus is made of two galvanized steel tubes with inner and outer diameter of $54.5 \mathrm{~mm}$ and $60.3 \mathrm{~mm}$ for the inner tube and 68.08 and $88.9 \mathrm{~mm}$, for outer one, respectively. The tubes of the outer 
annulus are assembled coaxially via two steel flanges by welding so that the inner diameter of the flanges equals the inner diameter of the inner tube of the outer annulus. The length of the annuli is fixed at $500 \mathrm{~mm}$. Variable numbers of semi circle of baffles are used circumferentially around the rotating tube. The diameter of buffle is equal to $52 \mathrm{~mm}$ and $2 \mathrm{~mm}$ thickness as shown in Fig.(3). Two copper tubes of $6 \mathrm{~mm}$ each are welded on the outer periphery of the outer tube of the outer annulus at the beginning and end of it. These copper tubes are connected to the heating circuit. The inner annulus as shown in Fig 2 consists of the inner tube of the outer annulus as its outer tube while the inner tube of it is made out of PVC of variable outer diameter of $21,26.7$ and $33.5 \mathrm{~mm}$. The inner tube is belt driven by an electric motor of $1 / 2 \mathrm{Hp}$ and of 1477 r.p.m. The surface temperature of the inner tube of the outer annulus is measured by four thermocouples embedded within the tube wall at various axial locations as shown in fig 2. Additional thermocouple is used to measure the ambient room temperature. Two thermocouples are used to measure hot water inlet and outlet temperatures and two thermocouples, are used to measure cold water inlet and outlet temperatures. All thermocouples are of $(\mathrm{k})$ type. The inner rotated tube of the annulus is provided with semi-circular radial buffles to enhance heat transfer. The buffles are equally space distributed on the outer surface of the rotated tube with variable number. The numbers of buffles used are 2,4,6, and 8 with longitudinal pitches of 166,100,71.4 and 55.5 which gives a pitch to tube diameter ratios of 6,3.6,2.57 and 2 .

\subsection{Hot water system}

The hot water system consists of a cylindrical tank of volume 150 liters, provided by an electric heater of $2000 \mathrm{~W}$ power, and a thermostat to adjust the temperature of the hot water. The hot water is flowing inside the outer annular gap at a prescribed constant temperature.

\section{Experimental Operation and Procedure}

Three values can be varied independently in this system. The speed of rotation of the inner cylinder, the gap thickness (inner cylinder diameter), and the velocity of cold water inside the annular gap. For a given combination of these parameters, the outlet temperature of cold water will eventually, reach a certain fixed value, when this value is obtained, the system is in a state of equilibrium. This condition is ascertained by measuring water temperature at selected time intervals and observing any changes. When these changes become small (Within \pm $0.1^{\circ} \mathrm{C}$ ), the steady state condition is assumed. For every case studied, the equilibrium time was approximately 30 minutes to be certain that the values recorded are representative at the steady state. This value is used in subsequent calculations.

Determining the heat transfer results in stationary annular tubes of different radius ratio and comparing them with the available correlation first standardized the experimental set up. Steady state values of mean Nusselt number for uniform temperature cooling of water then determined with each of the different radius ratio annular tube for different speed of rotation of the inner tubes of the annuli. The characteristics of stationary annular tubes as well as rotational ones are shown in table (1) 


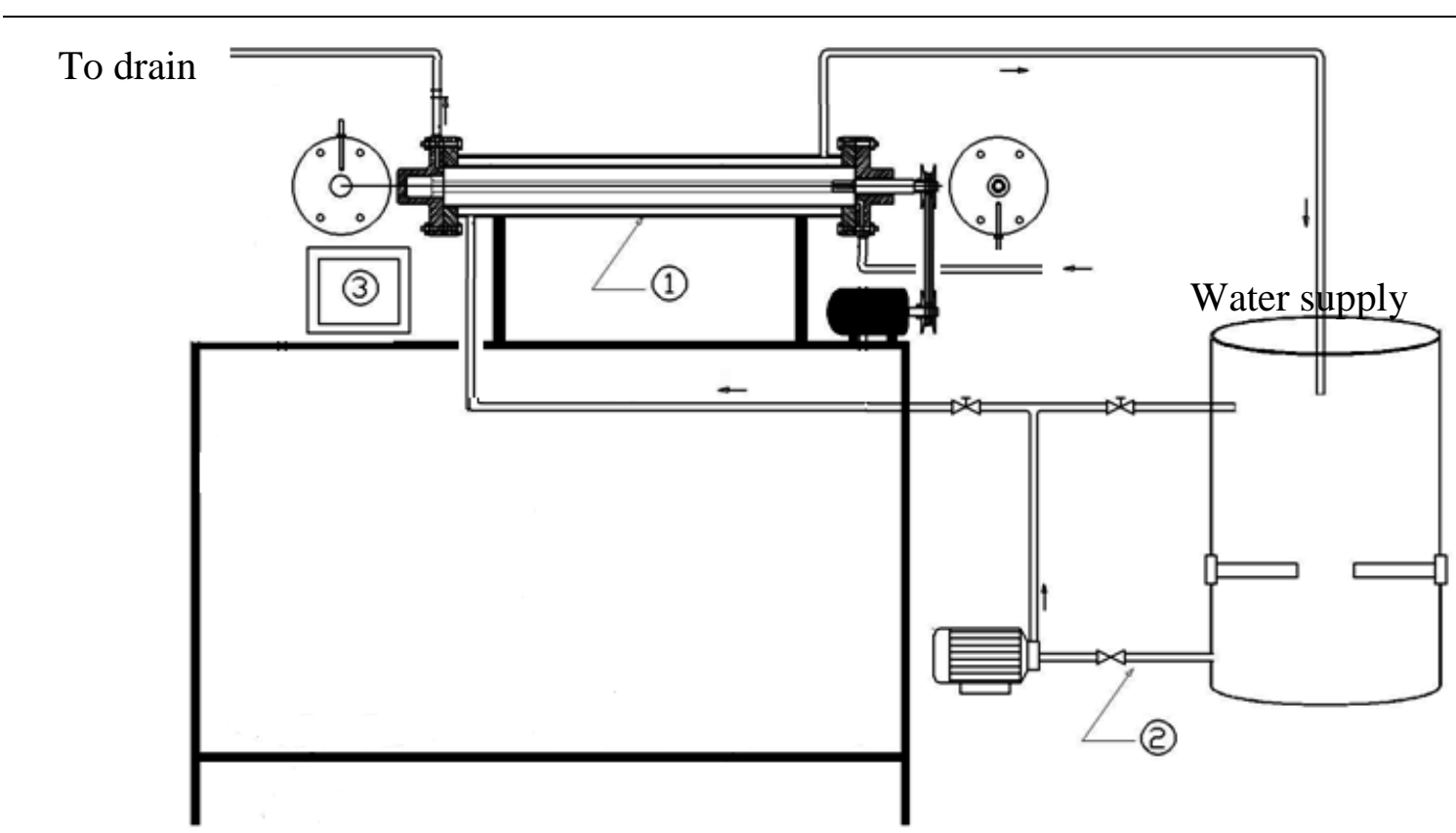

1. Test section

2. Hot water system

3. Temperature recorder

Fig.(1) Experimental Test Rig

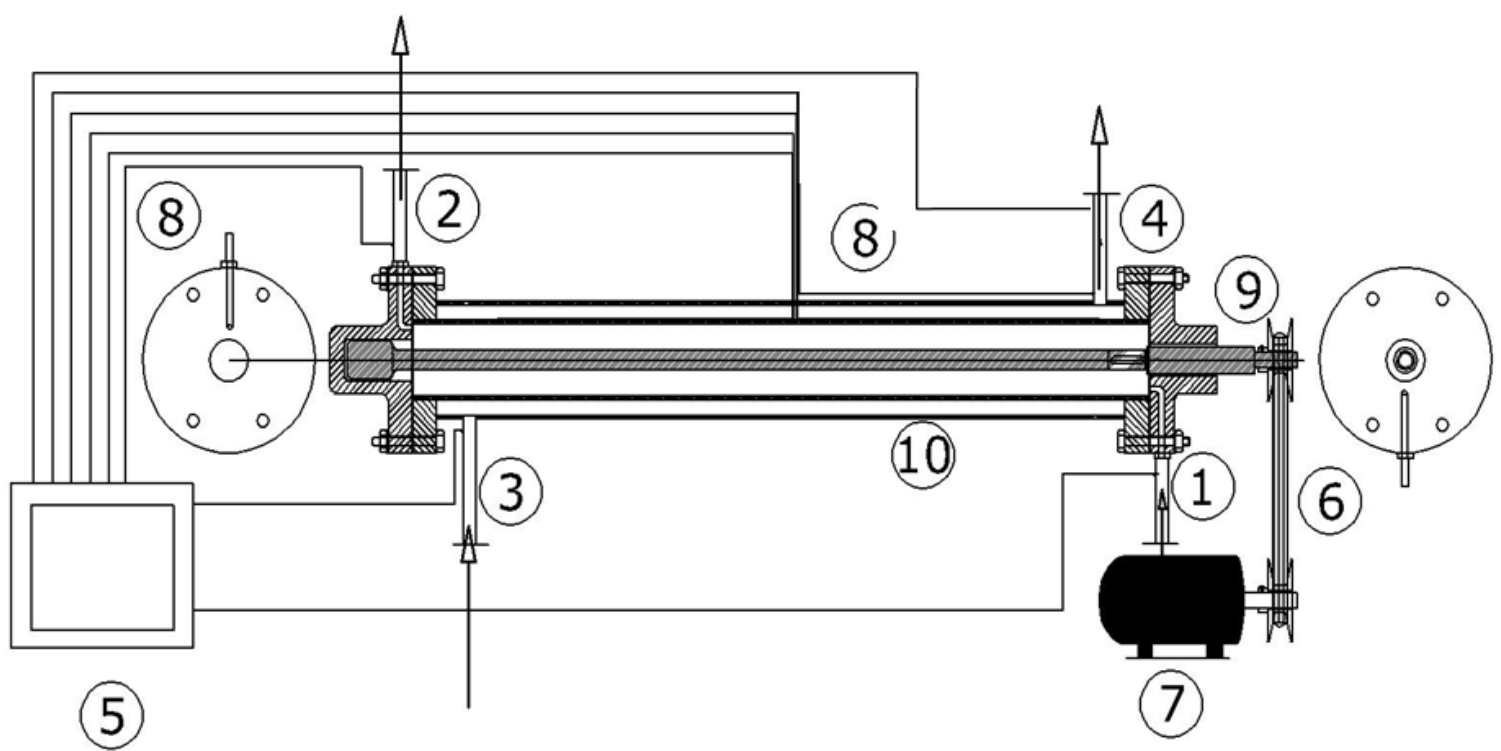

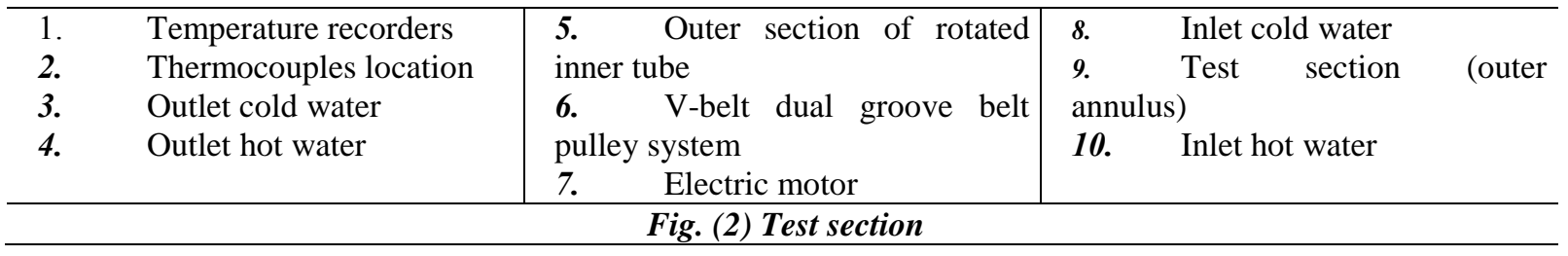




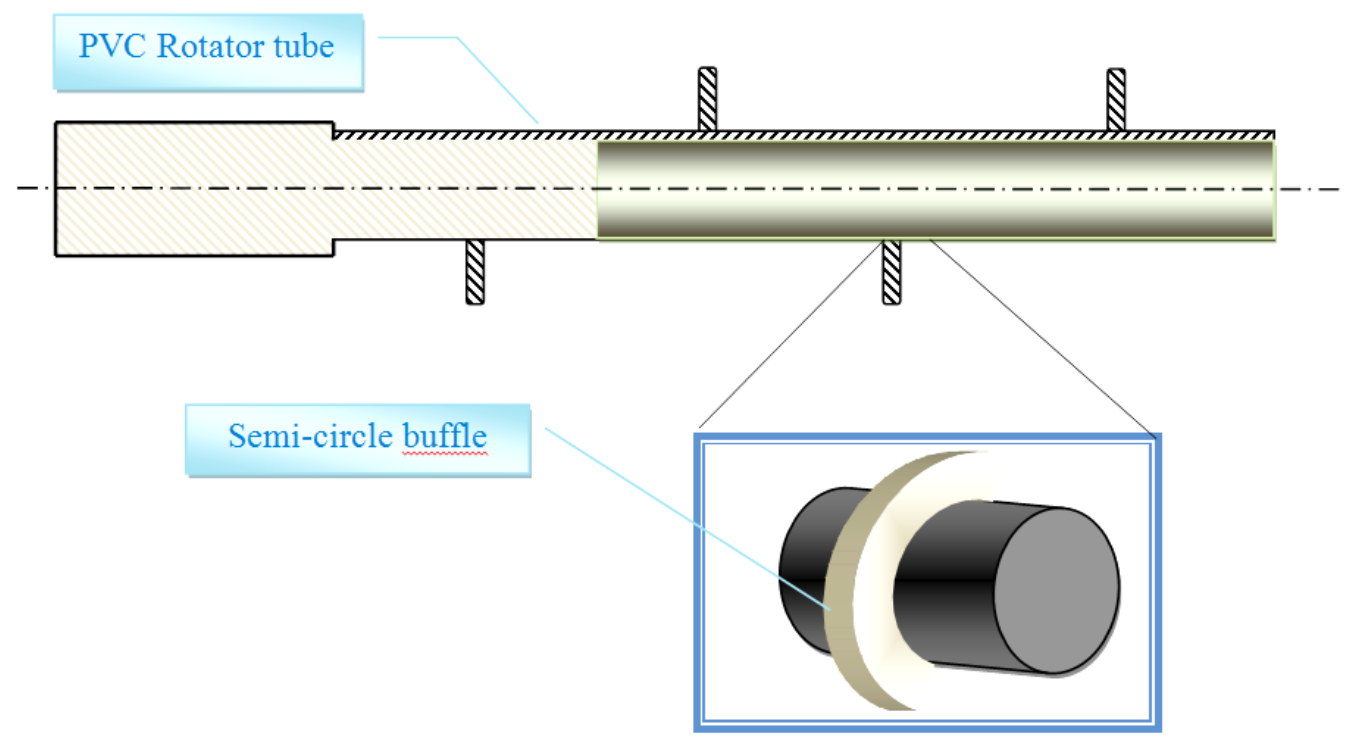

Fig. (3) Rotating inner tube with baffles

Table 1 characteristic of annular tubes

\begin{tabular}{|c|c|c|c|c|c|}
\hline Tube & di & do & D $_{\text {h }}$ & N & Buffle \\
\hline No. & mm & mm & mm & rpm & No. \\
\hline 1 & 33.5 & 54.4 & 20.9 & $\mathbf{0}$ & 0 \\
\hline 2 & 26.7 & 54.4 & 27.7 & 0 & 0 \\
\hline 3 & 21 & 54.4 & 33.3 & 0 & 0 \\
\hline 4 & 26.7 & 54.4 & 27.7 & $175-650$ & 0 \\
\hline 5 & 26.7 & 54.4 & 27.7 & 480 & $2-8$ \\
\hline
\end{tabular}

\section{Data Reduction}

From the detailed constructions of the annular tubes described in table 1, the annulus cross sectional area can be set as:

$$
A_{C}=\frac{\pi}{4}\left(D^{2}-d^{2}\right)
$$

The volumetric diameter defined as four times the volume for flow divided by the area of the wetted surface is used as the hydraulic diameter, $D_{h}$ for the case of comparison with the available literature. The hydraulic diameter can be expressed as:

$$
D_{h}=(D-d)
$$

Based on hydraulic diameter as a characteristic length, axial Reynolds number of the flow through the annulus Re can be is given:

$R_{e a}=\frac{u D_{h}}{v}$

Nusselt number of the annular tube $\mathrm{Nu}$ based on the hydraulic diameter can be written as: 
$N u=\frac{h D_{h}}{k}$

The heat transfer coefficient through the outer surface of the annular tube can be calculated from the heat balance equation described as.

$Q=m c_{p}\left(T_{w o}-T_{w i}\right)$

$=h A(L M T D)$

Where LMTD is the logarithmic mean temperature difference defined as:

$L M T D=\frac{\left(T_{w i}-T_{S}\right)-\left(T_{w O}-T_{S}\right)}{\ln \left[\left(T_{w i}-T_{S}\right) /\left(T_{w O}-T_{S}\right)\right]}$

The effect of rotational speed of the inner tube may be accounted for by the rotational Reynolds number $\operatorname{Re}_{\omega}$ based on hydraulic diameter and the inner diameter of the annular tube as a characteristic length. This rotational Reynolds number can be written as:

$R e_{\omega}=\omega \dot{\omega} \times d \frac{D_{h}}{2 v}$

Where

$\omega^{\prime}=2 \pi \frac{N}{60}$

\section{Results and discussion}

Laminar forced convection of water flowing through annular tubes having rotational inner tube is studied experimentally. The outer tube of the annulus is subjected to a hot stream of water flowing through the outer annulus while the inner wall is insulated. The effect of axial Reynolds number $\mathrm{Re}_{\mathrm{a}}$, rotational Reynolds number, $\mathrm{Re}_{\omega}$ and radii ratios of the annular tube $d / D$ on heat transfer rates will be discussed in the following sup sections.
Tests are performed at different radii ratio (0.386, 0.49, and 0.62) while both axial and rotational Reynolds number are varied over the range of 612 up to 2156 , and 7808 up to 22012, respectively.

\subsection{Validation of the experimental results}

Before reporting the main results of the present work, mention will be made of relevant auxiliary experiments. To demonstrate the validity of the experimental apparatus, heat transfer experiments were performed with stationary annular tube of radius ratio 0.487 in order to compare with heat transfer results in the literature. The relation between Nusselt number and axial Reynolds number based on the hydraulic diameter of the annular tube with radius ratio of 0.49 is presented in Fig.(3) as well as a straight line representing the correlation of sultan et al; [13]. It is concluded from the figure that the present experimental results for stationary annular tube with radius ratio of 0.49 are in fair agreement with the literature.

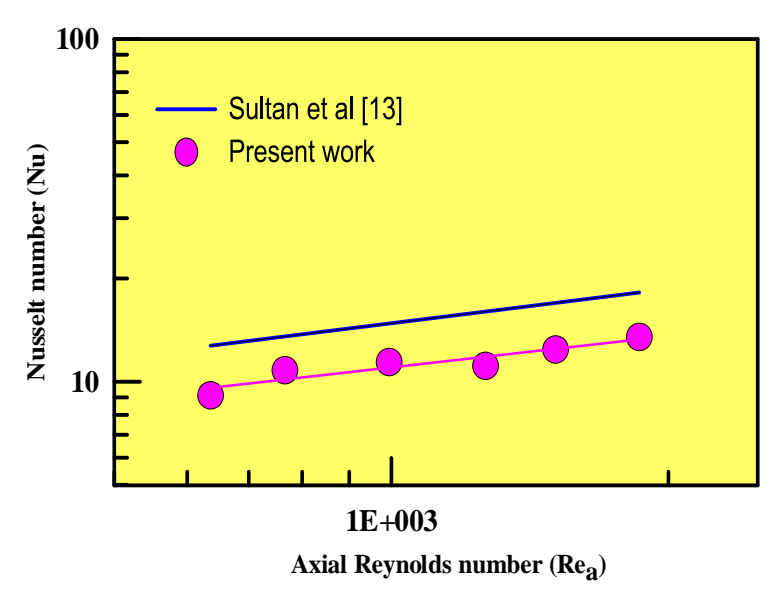

Fig. (3) Relation between $\mathrm{Nu}$ and Re for smooth anular tube for radius ratio 0.49

\subsection{Stationary annular tube}

results Experimental results for stationary annular tubes of radii ratios of $0.62,0.49$ and 0.386 are presented in Figure (4). It can 
be seen that Nusselt number increases with Reynolds number. It is also noticed that Nusselt number varies with the radius ratio.

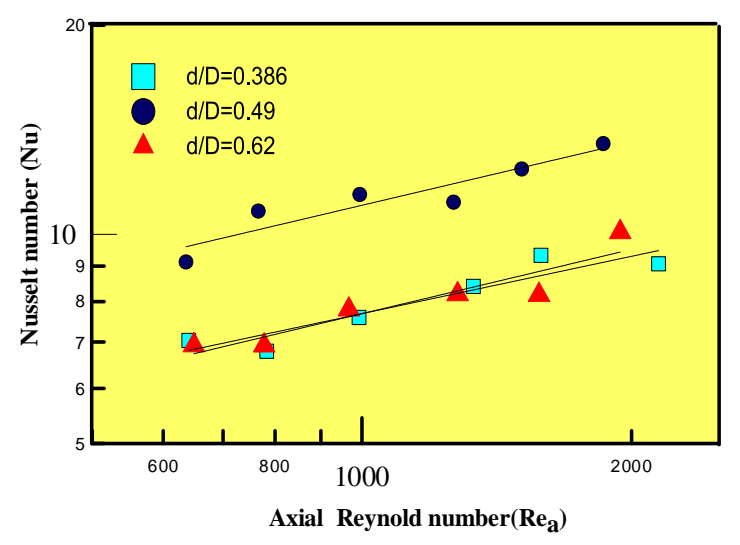

Fig. (4) Relation between Nu and Rea for smooth annular tube with different radii ratios

\subsection{Rotational annular tube results}

Attention will now be turned to the heat transfer results of rotational annular tubes. In this connection the sequence in which the experiments were performed was chosen in order to facilitate the presentation of results. For a specified value of radius ratio (d/D), Successive experiments are carried out with different values of rotational Reynolds number, $\operatorname{Re}_{\omega}$ one at a time. The axial Reynolds number, $\operatorname{Re}_{\mathrm{a}}$ value is changed for each rotational Reynolds number in order to cover its specified range each time.

The heat transfer coefficients of the outer surface of the annular tubes in case of laminar flow of water through the annular space were analyzed in terms of $\mathrm{Nu}-\mathrm{Re}_{\mathrm{a}}$ relationships. Fig. (5) shows the variation of Nusselt numbers, $\mathrm{Nu}$ with Reynolds number, $\mathrm{Re}_{\mathrm{a}}$ for annular tubes of radius ratio of 0.49 , at different rotational speeds of $650,570,480,400,350,215$ and 175 r.p.m. The Figure shows that for the rotational speed of nearly 480 r.p.m ( $\operatorname{Re}_{a}=2175$ nearly) produce a maximum increase in Nusselt number of the order of $79 \%$. At the same rotational speed of 480 r.p.m, but $\left(\mathrm{Re}_{\mathrm{a}}=646.2\right.$ nearly) yielded an increase of only $11 \%$ in Nusselt number, compared to the results of the stationary annular tube of the same radius ratio.

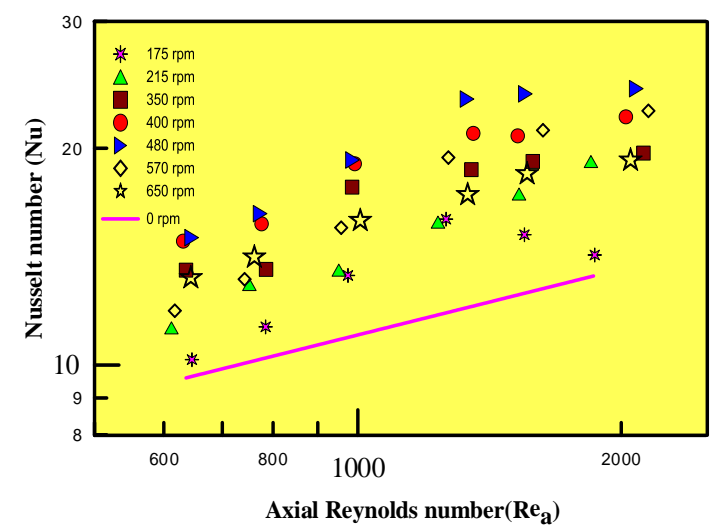

Fig.(5 ) Effect of speed of rotation on Nusselt number

The effect of rotational speed (rotational Reynolds number) on the heat transfer rate can be shown from Fig.(6). It is seen from the figure that Nusselt number increases with the increase of rotational Reynolds number and axial Reynolds number.

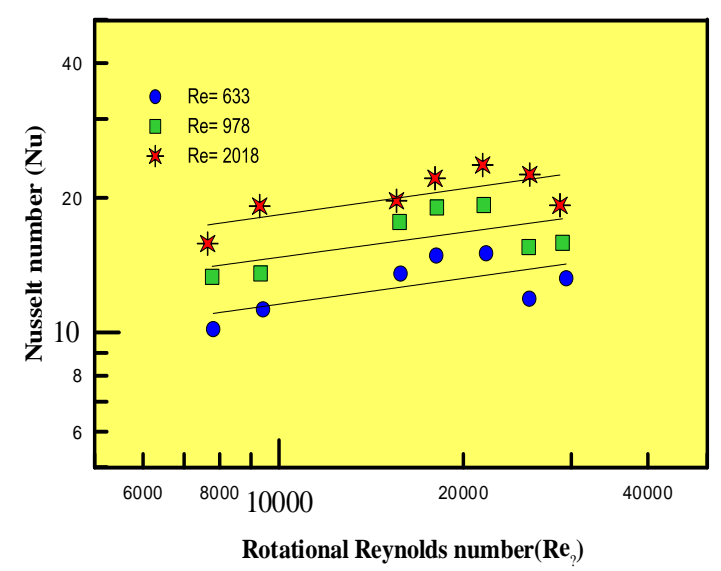

Fig, (6 ) Relation between Nusselt number and rotational Reynolds number 


\subsection{Rotational annular tubes correlation}

An attempt is made to correlate the data of rotational annular tube of different radius ratio.

A successive least square fit of the present. Experimental data of rotational annular tube of different radii ratios give the following correlation:

$\mathrm{Nu}=0.289 \operatorname{Re}^{0.304}(\mathrm{~d} / \mathrm{D})^{-0.117} \operatorname{Re}_{\omega}^{0.19}$

In the following operating ranges:

$612 \leq \operatorname{Re} \leq 2147,7646 \leq \operatorname{Re}_{\omega} \leq 29434$ and $=0.49$

The above correlation predicts the values of Nusselt number, which agree with the experimental results within $\pm 18 \%$ as shown in Fig. (7).

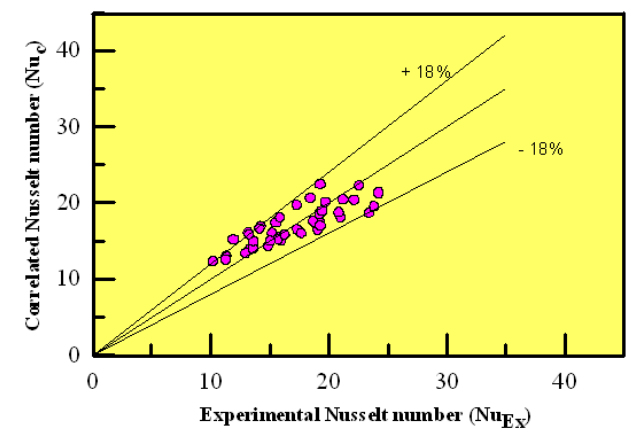

Fig. (7).Comparison between correlated and experimented $\left(\mathrm{Nu} u_{E X}\right)$ for fotating annulus

\subsection{Buffled rotational annular tube results}

Fig.(8) shows the relation of Nusselt number and axial Reynolds number for buffled tube with different pitch to diameter ratio with a fixed rotational speed $\left(\operatorname{Re}_{\omega}=22126\right)$. It is seen from the figure that Nusselt number greatly affected by the existance of buffles and increases with the decrease of pitch to diameter ratio. That may be due the over mixing of flowing water with the rotation of buffles. In order to show the effect of pitch to diameter ratio on Nusselt number elimination of axial Reynolds number occures using the complex $\mathrm{Nu} / \mathrm{Re}^{\mathrm{n}}$. The power $\mathrm{n}$ is calculated from the results presented in Fig.(8) and is equal to 0.485 . The complex $\mathrm{Nu} / \mathrm{Re}^{0.485}$ is presented in Fig. (9) as a function of buffle pitch to diameter ratio. It is seen from the figure that Nusselt number increases with buffles pitch until in reaches a maximum value at $(\mathrm{P} / \mathrm{d}=2.57)$ and then decreases with further increase in $(\mathrm{P} / \mathrm{d})$.

An attempt is made to correlate the data of buffled annulus as above in the rotational annular tube correlation under the different parameters affect the heat transfer process.

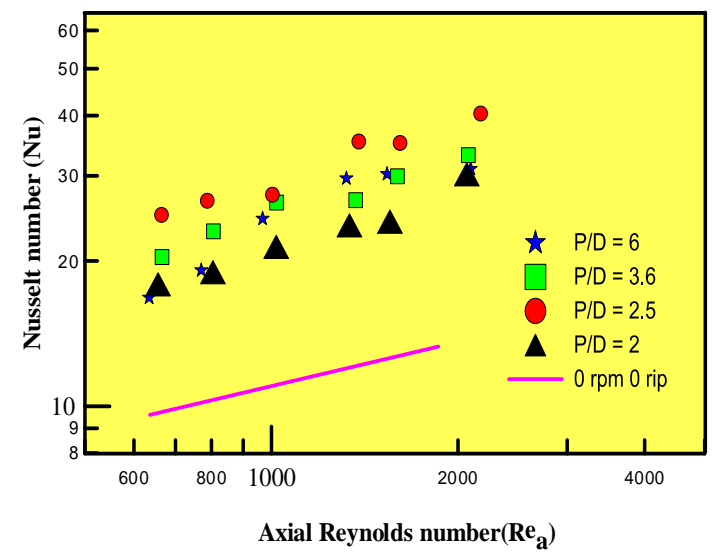

Fig. (8) Effect of number of rips on Nusselt number

$\mathrm{Nu}=0.12 \operatorname{Re}^{0.49}(\mathrm{~d} / \mathrm{D})^{-0.117} \operatorname{Re}_{\omega}{ }^{0.19}$ $(\mathrm{P} / \mathrm{D})^{-0.036}$

In the following operating ranges:

$634 \leq \operatorname{Re} \leq 2175, \quad 21524 \leq \operatorname{Re}_{\omega} \leq 2252$ and $\mathrm{d} / \mathrm{D}$ $=0.49$

The above correlation predicts Nusselt number value with $\pm 18 \%$ deviation as shown in Fig. (10) 


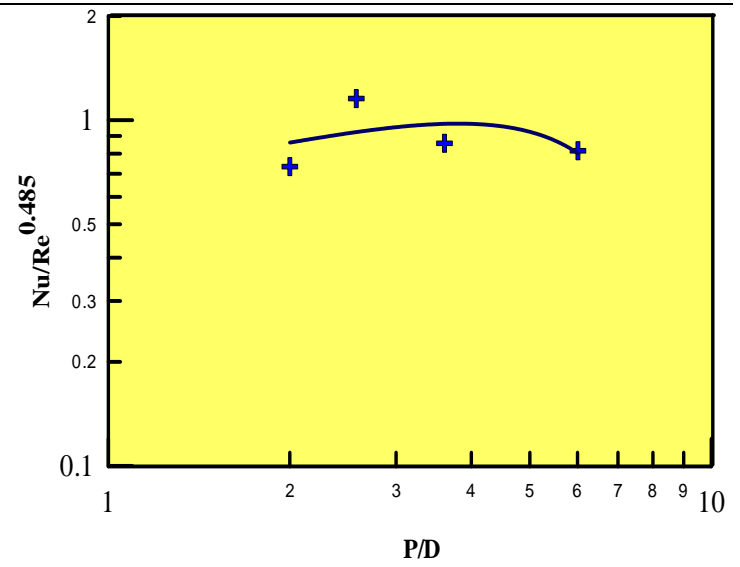

Fig.(9) Effect of buffle pitch to tube diameter ratio on Nusselt number

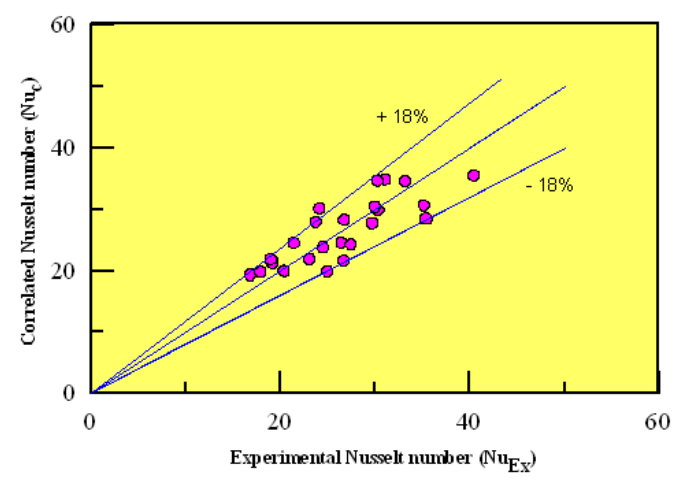

Fig.(10) Comparison between the proposed correlation and Exp-data for rotating buffled annulus

\section{Conclusions}

From the results of experimental investigations of stationary and rotating annuli, the following conclusions may be drawn:

1- Nusselt number increases with Reynolds number for both stationary and rotated annuli.

2- Nusselt number has the biggest value at diameter ratio equal to 0.49 .

3- Rotation without buffle, Produces a maximum increase in Nusselt number of the order of $79 \%$ at $\mathrm{Re}_{\mathrm{a}}=2080$, $\operatorname{Re}_{\omega}=21545$ and rotational speed $=480$ r.p.m, (increase of only $11 \%$ in Nusselt number at $\operatorname{Re}_{\mathrm{a}}=646.2, \quad \operatorname{Re}_{\omega}=7808$ ,(rotational speed of 175 r.p.m), compared to the results of the stationary annular tube of the same radius ratio .

4- Nusselt number increases with Reynolds number and with the number of buffels until it reaches its maximum value at pitch to diameter ratio $\mathrm{P} / \mathrm{D}=$ 2.57 ,then is decreases with further increase (P/D).

5- Rotation with buffle, Produces a maximum increase in Nusselt number of $200 \%$ at $\operatorname{Re}_{\mathrm{a}}=2175, \mathrm{Re}_{\omega}=21884$ and rotational speed $=480$ r.p.m, and increase of only $84 \%$ in Nusselt number at $\operatorname{Re}_{\mathrm{a}}=634, \quad \operatorname{Re}_{\omega}=21778$ ,(rotational speed of 175 r.p.m) compared to the results of the stationary annular tube of the same radius ratio ..

6- Two correlations are made to describe the relation between Nusselt numbers and axial Reynolds number, diameter ratio, pitch to diameter ratio $\mathrm{P} / \mathrm{D}$ and rotational Reynolds number.

\section{References}

[1.] W. Reynolds, R. Lundberg, and P. Mcuen, "Heat transfer in annular passages. General formulation of the problem of arbitrarily prescribed wall temperatures or heat fluxes", Int. J. Heat and Mass Transfer, Vol.6, No.5, pp.483-493 (1963).

[2.] H. Heaton, W. Reynolds and W. Kays, "Heat transfer in annular passages. Simultanious development of velocity and temperature fields in laminar flow", International Journal of Heat and Mass Transfer, Vol. 5, pp.763-781 (1964).

[3.] E. Sparrow and S. Lin, "The developing laminar flow and pressure drop in the entrance region of annular ducts", Journal of the Basic 
Engineering Transactions of the AS ME, Vol. 86, pp. 827-834 (1964).

[4.] M. El-shaarawi and M. Alkam, "Transient forced convection in the entrance region of concentric annuli", Int. J. Heat Mass Transfer 35 .33353344 (1992).

[5.] J. Yoo, "Mixed convection of air between two horizontal concentric cylinders with a cooled rotating outer cylinder", International journal of Heat and mass transfer, vol. 41, no.2, pp 293-302 (1998).

[6.] N. Islam, U. Giatnode and G. Sharman, "Mixed convection heat transfer in the entrance region of horizontal annuli", Int. J. of Heat and Mass Transfer 44 2107-2120. (2001).

[7.] E. Soares, M. Naccache and $P$. Mendes, "Heat transfer to viscop1astic materials flowing axially through concentric annuli", Int. J. of Heat and Fluid Flow 24. 762-773. (2003).

[8.] A. Eraslan and T. Ozbelge, "Assessment of flow and heat transfer characteristics for proposed solid density distributions in dilute laminar slurry upflows through a concentric annulus", Chemical Engineering Science, Volume 58, Issue 17, Pages 4055-4069. (2003).

[9.] C. llicali and S. Engez, "Laminar flow of power law fluid foods in concentric annuli", Journal of Food Engineering, Volume 30, Issues 3-4, Pages 255-262 (1996).

[10.] W. Sutherland and W. Kays, "Heat transfer in an annulus with variable circumferential heat flux", International Journal of Heat and Mass Transfer, Volume 7, Issue 11, Pages 1187-1192 . (1964).

[11.] G. Lu, Z. Sun, Wang and C. Yan, "Experimental study on heat transfer characteristics of flow in a narrow annular duct", Dongli Gongcheng
Power Engineering, vol. 25, pp 275279 (2005).

[12.] Tzer-Ming Jeng ,Sheng-Chung Tzeng,"Heat transfer enhancement of Taylor-Couette flow in an annulus by mounting longitudinal rips on the rotating inner cylinder",Int.J.Heat and Mass Transfer, Vol.50,No.12,pp381390(2007).

[13.] Y.E.Abdel Ghaffar and Ahmed A.Sultan, "Expermintal investigation of forced convection heat transfer from outer surface of annular tube with rotating inner tube", Mansoura Eng.Joumal,(MEJ),Vol.30,No.2,pp.4152, (2005).

[14.] D.Aliean, "Experimentally investigated overall heat transfer coefficient for a rotating cavity type heat exchanger" Heat Mass Transfer 11 1345-3332. (1990).

[15.] W. Mollo, E. Astill, S. Leal, "Convective heat mass transfer in the entrance region of a concentric annulus having a rotating inner cylinder", Int. J Heat and Fluid Flow 11 120-128 (1990).

[16.] J. Choi and M. Kim, "Threedimensionality linear stability of mixed convective flow between rotating horizontal concentric cylinders", International journal of Heat and mass transfer, vol. 38, no.2, pp 275-285. (1995).

[17.] Escudier, I W Gouldson, 1995. Concentric annular flow with center body rotation of a Newtonian and a shear- thinning liquid, International Journal of Heat and Fluid Flow Vol. $16,156-162$. 